\title{
The Ethics of Veracity and It Is Importance in the Medical Ethics
}

\author{
Ahmed Bait Amer \\ Sultan Qaboose University Hospital, Muscat, Oman \\ Email: ahmedsaid-777@hotmail.com
}

How to cite this paper: Amer, A.B. (2019) The Ethics of Veracity and It Is Importance in the Medical Ethics. Open Journal of Nursing, 9, 194-198.

https://doi.org/10.4236/ojn.2019.92019

Received: January 14, 2019

Accepted: February 22, 2019

Published: February 25, 2019

Copyright (C 2019 by author(s) and Scientific Research Publishing Inc. This work is licensed under the Creative Commons Attribution International License (CC BY 4.0).

http://creativecommons.org/licenses/by/4.0/

\begin{abstract}
The goals of this overview is to discuss the ethics of telling the patient the truth, with some historical backgrounds and it is importance in medical practice, Justifying Less than Full Disclosure in some situations in which the truth may have a terrible impact on the occasional patient, and the influence of the culture on the health care professionals attitudes towards telling the patient the truth. Conclusion: The health care professionals need more awareness, and training in ethics of veracity and also in the communication skills especially in the context of breaking bad news in telling the patient the truth about diagnosis, treatment outcomes, and prognosis of any serious illness.
\end{abstract}

\section{Keywords}

Telling the Truth, Ethics, Veracity, Virtue

\section{Introduction}

The debate on the issue of truth telling is at the core of the contemporary biomedical ethics. There is delicate interplay between autonomy and beneficence which made some differences in truth telling between the cultures, from the in medicine [1]. Truth-telling in medicine is a broad area and often encompasses several ethical issues. These issues include the right of patients or their families to receive information about their diagnosis and illness [2]. The standard of professional candor with patients has undergone a significant change over the past 30 years. Independent of their obligation to disclose information necessary for informed consent, physicians are increasingly expected to communicate important information to patients that is not immediately related to treatment decisions [3].

\section{Veracity as a Virtue}

In the beginning we have to know what is virtue; then what is the meaning of 
veracity. A virtue is a feature of one's character: a disposition to act in a certain way in relevant circumstances that will make you a good person [4] [5]. What is veracity? In concise oxford dictionary veracity is conformity to facts, accuracy, habitual truthfulness [6]. Henry Sedgwick's nineteenth-century observation still holds: "It doesn't clearly agreed whether veracity is an absolute and independent obligation, or a special application of some higher principle". G. J. Warnock's later assessment was that veracity is an independent principle and virtue that ranks in importance with beneficence, nonmaleficence, and justice, we view obligations of veracity as specifications of more than one principle [1].

\section{Veracity in the Health Care Setting}

It refers to comprehensive, accurate, and objective transmission of information, as well as to the way the professional fosters the patients or subjects understanding. In this regards, veracity is closely connected to respect of autonomy [1]. Bacon's comment that "knowledge is power but honesty is authority", is particularly applicable to doctors [7].

\section{History of the Ethics of Veracity}

The historical medical codes addressed issues like not doing harm, not taking life, not engaging in sexual acts, not revealing secrets, but said little or nothing about telling the truth and avoiding lie [6], the codes of medical ethics have traditionally ignored obligations and virtues of veracity [1]. The historical absence of a truth requirement in medical ethics has much to do with the moral assumptions of ancient cultures. In earlier cultures it was an ideal to treat other persons as a father treats a child. Paternalism was something virtuous; the opposite was to treat the other as a slave. In early Greek culture, the good doctor or the good ruler treated the patient or the citizen as a son or daughter rather than a slave. He did what was best for the "child" but without ever asking for his or her consent [6]. The Hippocratic Oath does not recommend veracity nor does the Declaration of Geneva of the World Medical Association. The principles of Medical Ethics of the American Medical Association (AMA) from it is origins until 1980 made no mention of an obligation or virtue of veracity, giving physicians unrestricted discretion about what to divulge to patients [1]. The 1980 revision recommended that a physician shall deal honestly with patients and colleagues and strive to expose those physicians deficient in character or competence, or who engage in fraud or deception. This first official reference to veracity in physician codes remains a very abstract one, and is more concerned with failures of honesty among colleagues than with truth telling to patients [6] and the 2001 revision indicates that physicians shall "be honest in all professional interactions". Despite this traditional neglect of veracity, the virtues of candor, honesty, and truthfulness are among widely and deservedly praised character traits of health professionals and researchers [1]. 


\section{Importance of Ethics of Veracity in the Medical Ethics}

When physicians communicate with patients, being honest is an important way to foster trust and show respect for the patient. Patients place a great deal of trust in their physician, and may feel that trust is misplaced if they discover or perceive lack of honesty and candor by the physician [7].

Today, patients have the right to know their health information, and physicians are obliged to provide it. It is expected that patients will be informed of their medical condition regardless of the severity or prognosis [8]. What is of importance is the way that information should be given to patients. A good truth telling technique could have positive effects on their prognosis and quality of life, reducing emotional pressure and maintaining their sense of hope [9]. Truth telling does not mean that health care professionals must simple disclose all the information bluntly in one session. It is very important while sharing medical information nothing remains uncertain. Doctor has to be aware of the way that truth is affecting each patient and respond in an empathetic and attentive manner [10]. Telling the patient the truth ensures that the correct information is given and correct choice for the patient is made. Explaining the truth to the patient is a very complicated process and the physicians experience is very important, a physician who has developed communication skills and knows approaches for informing can give desired messages that give the amount of information that the patient wants and when the patient is ready [11]. Truth telling fosters trust in the medical profession and rests on the respect owed to patients as persons. It also prevents harm, as patients who are uninformed about their situation may fail to get medical help when they should [12]. Truth-telling obviously is a necessary condition of medical practices but could at times be withheld in order to avoid another vital interest that may help in promoting the healing process which the intervention hopes to achieve [13] [14].

\section{Justifying Less than Full Disclosure}

Withholding information from a patient does not always undermine veracity or violate the truth principle. Sometimes patients request that information be withheld. Doctors sometimes are asked to make decisions for patients without communicating relevant information. Ordinarily, respecting such requests violates no major ethical principle: neither autonomy, nor truth, nor beneficence [6]. According to Korsch and Harding, "The information a doctor gives a patient should be tempered by who the patient is and what he or she is ready to hear". In addition, many contextual variables - the doctor, the patient, the condition, the time frame, the need for privacy, the patient's expectations, the complexity of the condition, the implications of illness, and the nature of the interaction-influence the sharing of information [15]. So clinical judgment is always required because in some cases, even a reluctant and intimidated patient who requests not to be informed, needs to know some truths. Not knowing may create a serious danger 
to self or to others, and if so, the patient's request that information be withheld cannot be respected because it violates the core principles of beneficence and nonmaleficence [6].

The following Case is an example: a 65-year-old man comes to his physicians with complaints of abdominal pain that is persistent but not extreme. Workup reveals that he has metastatic cancer of the pancreas. The man has just retired from a busy professional career, and he and his wife are about to leave on a round-the-world cruise that they've been planning for over a year.

Should you tell him his diagnosis?

\section{Discussion of the case}

Several factors tempt one to withhold the diagnosis, and these should be recognized. One would be the concern that the patient would suffer psychological harm that would interfere with his planned trip. There is little empirical evidence that this occurs, and lacking some compelling reason to think it would occur with this man, it is insufficient grounds to withhold information. To the contrary, sensitive disclosure would allow the patient and his wife to decide if the trip is still important to them, versus seeing their grandchildren, for instance, and would spare the patient the inconvenience of suffering advancing symptoms while traveling, perhaps necessitating emergency care in a foreign locale. Finally, physicians should not confuse discomfort at giving bad news with justification for withholding the truth. In this case, the man should be told his diagnosis, prognosis, and treatment options [7].

\section{The Ethics of Veracity and Cultural Influence}

Cultures that place a higher value on beneficence and nonmaleficence relative toautonomy have a long tradition of family-centered health care decisions. In this collective decision process, relatives receive information about the patient's diagnosis and prognosis and make treatment choices, often without the patient's input [16]. Family members acting as surrogates for their loved ones often request that the truth be withheld, usually to prevent what is perceived as possible terrible harm to their loved one. Physicians may have to work closely with these family members to make sure that their patients are well cared for and their autonomy respected while acknowledging the critical role that loving family members play in the process of achieving desirable care [17].

\section{Conclusion}

The health care professionals needs more awareness, and training to increase their skills in the ethics of veracity and also the communication skills especially in the context of breaking bad news in telling the patient the truth about diagnosis, treatment outcomes, and prognosis of any serious illness; such skills have been found to improve doctor-patient relationship, satisfaction with care and patient health outcomes. 


\section{Conflicts of Interest}

The author declares no conflicts of interest regarding the publication of this paper.

\section{References}

[1] Beauchamp, T.L. and Childress, J.F. (2009) Principles of Biomedical Ethics. 6th Edition, Oxford University Press, USA.

[2] Amer, A.B. and AL-Zakri, N. (2013) A Qualitative Study of the Omani Physicians' Lived Experience with Truth Disclosure to Cancer Patient. Open Journal of Nursing, 3, 130-137. http://www.scirp.org/journal/ojn/ https://doi.org/10.4236/ojn.2013.31017

[3] Hébert, P.C., Hoffmaster, B., Glass, K.C. and Singer, P.A. (1997) Truth Telling. Bioethics for Clinicians. Canadian Medical Association Journal, 156.

[4] Sullivan, R.J., Menapace, L.W. and White, R.M. (2001) Truth-Telling and Patient Diagnoses. Journal of Medical Ethics, 27, 192-1975.

[5] Nigel, W. (2006) Philosophy the Classics. 3rd Edition, Routledge Taylor \& Francis Group, Abingdon.

[6] Pearsal, J. (1999) Concise Oxford Dictionary. 10th Edition, Oxford University Press, Oxford, 1591.

[7] Drane, J.F. (2002) Honesty in Medicine: Should Doctors Tell the Truth? American Journal of Bioethics, 2, 14-17.

[8] https://depts.washington.edu/bioethx/topics/truthd2.html

[9] Sisk, B., Frankel, R., Kodish, E., Isaacson, J.H. and Perm, J. (2016) Summer, 20, 74-77.

[10] Tang, W.-R., Fang, T.-S., Chun-Kai Fang, C.-K. and Fujimori, M. (2013) Truth Telling in Medical Practice: Students' Opinions versus Their Observations of Attending Physicians' Clinical Practice. Psycho-Oncology, 22, 1605-1610. https://doi.org/10.1002/pon.3174

[11] Beste, J. (2005) Instilling Hope and Respecting Patient Autonomy: Recording Apparently Conflicting Duties. Bioethics, 19, 215-231. https://doi.org/10.1111/j.1467-8519.2005.00438.x

[12] Buken, N.O. (2003) Truth Telling Information and Communication with Cancer Patient in Turkey. JISHIM, 2, 31-36.

[13] Mobeireek, A.F., Al Kassimi, F., Al Zahrani, K., Al Shimemeri, A., al Damegh, S., Al Amoudi, O., Al Eithan, S., Al Ghamdi, B. and Gamal-Eldin, M (2008) Information Disclosure and Decision-Making: The Middle East versus the Far East and the West. Journal of Medical Ethics, 34, 225-229. https://doi.org/10.1136/jme.2006.019638

[14] Anifowosea, O.A. (2016) Virtue Ethics and Veracity in HIV/AIDS and Oncology Cases. Türkiye Biyoetik Dergisi, 3, 110-119. https://doi.org/10.5505/tjob.2016.28247

[15] Palmieri, J.J. and Stern, T.A. (2009) Lies in the Doctor-Patient Relationship. Primary Care Companion to the Journal of Clinical Psychiatry, 11, 163-168.

[16] Russell Searight, H. and Gafford, J. (2005) Cultural Diversity at the End of Life: Issues and Guidelines for Family Physicians. American Family Physician, 71, 515-522.

[17] Gordon, M. and Sokolowski, M. (2005) Protection from the Truth: A Challenge for Surrogates and Health Care Professionals. Annals of Long-Term Care, 13. 